\title{
CAÍN, O DE LA TRÁGICA FIDELIDAD \\ A LA TIERRA
}

\author{
FÉLIX DUQUE
}

Universidad Autónoma de Madrid

\begin{abstract}
RESUMEN: Al tratarse de un ensayo en hermenéutica, este trabajo no se pronuncia en absoluto sobre la verdad de un texto considerado sagrado por las tres grandes religiones del Libro, sino que se limita a indagar en su contexto y sondear en sus presupuestos, apoyándose ante todo por el impar drama Caín, de Lord Byron; y todo ello, a fin de sacar a la luz una arraigada creencia en el imaginario colectivo occidental, a saber: la desconfianza y menosprecio de la tierra, o sea de lo opaco, cerrado y retráctil, en favor de lo celestial, o sea de lo abierto y jerárquicamente mensurador. Tal distinción poco tiene que ver con la típica diferencia metafísica entre materialismo y espiritualismo (o gnoseológica entre realismo e idealismo); más bien habría que apuntar a la existente entre lo sagrado y lo santo, o sea entre lo refractario a lenguaje (pero latente en él, como una fisura imborrable) y lo sometido al lógos y domesticado por él.
\end{abstract}

PALABRAS CLAVE: Jardín / Tierra; Dios / Hombre; Ofrenda / Muerte; Ciudad / Errancia.

\section{Cain, or the tragic fidelity to Earth}

ABSTRACT: Since this is an essay on hermeneutics, this paper says nothing at all about the truth of a text deemed sacred by the three great religions of the Book but is confined to enquire into its context and sound out its assumptions, also relying on Cain, Lord Byron's unparalleled drama; and all this is intended to bring an entrenched belief in the West's collective imagination to light, namely, mistrust and contempt for the Earth, that is, for what is opaque, enclosed and retractable, in favour of the heavenly, in other words, of what is open and hierarchically measuring. Such a difference has little to do with the typical metaphysical difference between materialism and spiritualism (or the gnoseological one between realism and idealism); we should rather point out to the difference between what is sacredness and saintliness, that is to say, between what is unyielding to language (yet dormant in it, as an indelible crack) and what is subdued by logos and tamed by it.

KEY WORDS: Garden / Earth; God/ Man; Offering / Death; City/ Wandering.

De todos es sabido que el Dios bíblico es creador del cielo y de la tierra. Se atiende menos en cambio a que las relaciones de ésta con su Hacedor nunca han sido fáciles, hasta el punto de que, en la conocida formulación escolástica: creatio ex subjecti sui et nihilo, bien podría decirse que la nada no habría sido otra cosa que la abstracción metafísica de la tierra primigenia. En efecto, sabemos que la tierra, ya desde el inicio (el inicio de todo: del Libro y de la Creación en él recogida): «estaba confusa y vacía y las tinieblas cubrían la haz del abismo, pero el espíritu de Dios se cernía sobre las aguas». (Génesis 1, 2). Confusa y vacía: tohu wa wuhu, como Tiamat: el monstruo acuático del Enuma Elish babilónico.Y sin embargo, es de esa tierra yerma y salvaje, y no de la verdecida ya desde el Tercer Día, de donde habría formado Yavé al hombre, a pesar de que tan estupendo evento sucediera al final del Sexto Día. Es más, en la llamada «narración seca» del Génesis parece darse un orden inverso al de «los 
trabajos y los días» de Elohim, como si el hombre hubiera sido creado antes de que hubiera hierba y arbustos en el campo y de que la lluvia lo verdeciera: tan sólo una neblina rezumaba de la tierra, como si las aguas inferiores pugnaran por inundar la superficie.

Polvo y humedad, pues: barro, en fin. Tal es el poco alentador origen del hombre: «Formó Yavé Dios al hombre del polvo de la tierra, y le inspiró en el rostro aliento de vida, y fue así el hombre ser animado» ". El propio nombre de Adán ('âdâm) delata esa baja procedencia ('âamâh, en hebreo, es «tierra»), de modo que su destino natural sería (y acabará siendo en la edad presente del mundo, tras la Caída y hasta el Juicio Final) la disgregación ${ }^{2}$, si no fuese por el aliento divino que precariamente lo sostiene. También los griegos (Esquilo, en Los siete contra Tebas; y Platón, en Las leyes) hablarán del hombre como «Hijo de la tierra». Por su parte, en latín (y en consecuencia, en todas las lenguas romances), el término homo procede de humus: el manto orgánico de la tierra ${ }^{3}$.

Sólo que esa bajeza supone paradójicamente un privilegio ontológico. Pues, contra todo transformismo, de seguir la letra de la llamada "creación seca», nada le debe el hombre a la naturaleza (es más: cuando él fue formado, ni siquiera existía la Naturaleza: sólo un empapado desierto). En efecto, aquí -y contra la «creación húmeda» con la que comienza tradicionalmente el Génesis-, Adán, el hombre extremoso (barro por fuera, fogoso aliento divino por dentro) es anterior a todos los reinos de la naturaleza viviente, animal o vegetal: una prioridad que explicaría su primacía, la justificación de su dominio sobre todo ello. Pues — dejando aparte a los ángeles—él es el Primogénito de

1 Gen. 2, 7. En el relato caldeo de la creación, Marduk amasa barro con su sangre, formando así al hombre como una creatura híbrida, un monstruum formado por principios antagónicos: lo más bajo y pasivo (la tierra), sometido a lo más alto y activo (el dios). Más compleja y hermosa es la fábula 220 de Hyginus Polyhistor, que veinte siglos después recogerá Heidegger en Sein und Zeit Aquí no será un dios el que modele al hombre, sino un inquietante personaje femenino; inquietante, por ser la personificación de la inquietud misma: Cura. Fue ella la que, tras pasar un río, modeló en su ribera, a partir del "gredoso barro» (cretosum lutum), un cuerpo; y mientras deliberaba qué hacer después pasó por allí Júpiter, al cual rogó que infundiera espíritu en aquél (ut det illi spiritum). Por otra parte, en el mito griego es Prometeo quien forma primero al hombre, y quien le dona después el fuego que robara del Olimpo. En todos estos casos, empero, se trata de una infusión del principio de vida (sangre, aliento, spiritus) por parte de un dios.

2 Tras la caída, y la consiguiente expulsión del paraíso, Dios condena al hombre al trabajo fatigoso: «Hasta que vuelvas a la tierra. Pues de ella has sido tomado; Ya que polvo eres, y al polvo volverás». (Gen. 3, 19).

3 Adviértase sin embargo la diferencia. En la tradición judeo-cristiana, la procedencia a partir del polvo revela la absoluta dependencia del hombre respecto a Dios. En cambio, que el cuerpo del hombre haya sido formado, bien por la Previsión (que eso significa «Prometeo»), bien por el Cuidado, y formado a partir del rico humus (tierra orgánica, fecunda), implica una menor distancia entre lo divino y lo humano, una syngénia o consaguinidad (como recordará San Pablo a los atenienses, torciendo una creencia pagana en doctrina cristiana, en los Hechos de los Apóstoles 17, 28-29), ya que, en definitiva, dioses y hombres surgen de Cháos, de Physis o de Natura. La primera mención de la relación homo / humus se encuentra en las Institutiones de Quintiliano (I, V, 34). 
Dios. ${ }^{4}$ Esta anterioridad ontológica del hombre respecto a la Creación entera constituye una revelación sensacional - y como se ha apuntado, rabiosamente antidarwinista, por lo demás- que sólo puede ser, si no comprendida, sí al menos contextualizada, con tal de que recordemos que, en la tradición teándrica cristiana, al cabo ya de siempre el Hijo, la Segunda Persona de la Trinidad, era al menos in pectore un hombre, o mejor: el Hombre. Es verdad que en el libro de Job parece ponerse en duda esta primacía, para abajar el orgullo humano:

¿Eres tú, por ventura, el primer nacido?

¿Viniste al mundo antes que los montes?

¿Fuiste admitido a consejo con Dios

y acaparas en ti toda la sabiduría?

$(J o b ; 15,7-8)$.

Sin embargo, es conveniente recordar que esas interrogaciones son lanzadas en tono retórico por Elifaz contra el desdichado Job, que hartas razones habría tenido por demás para quejarse ante Dios de su destino. En cambio, el texto del Génesis no deja lugar a dudas sobre esta primacía: «Plantó luego

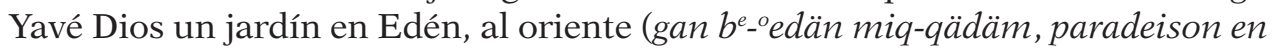
Edem katà anatolás), y allí puso al hombre a quien formara». (Gen. 2, 8; he subrayado el adverbio de tiempo). De donde se sigue, obviamente, que el hombre, hecho de la tierra yerma, era anterior al Jardín mismo. Como se ve, aquí Dios oficia de Jardinero Mayor. De Jardinero, y más: de Arquitecto del Paraíso, como «modelo» de lo que habría podido ser la tierra sin el pecado del primer hombre.

Por otra parte, el término paràdeisos fue introducido por la versión griega de los LXX, habiendo sido ya empleado por Jenofonte para referirse a los jardines reales persas (pairidaeza). Las tres características distintivas de éstos eran: 1) que se hallaban efectivamente en medio del yermo, fuera de la ciudad y del palacio (como una especie de pabellones de caza y recreo), 2) que estaban surcados por canales de riego, y 3) que eran cotos cercados, o sea: estaban protegidos y separados del entorno por una empalizada. El jardín, como un oasis, está circunscrito, limitado por todas partes por el desierto (o mejor, el desierto -Edén- aparece como tal, por vez primera, al ser plantado en su centro el jardín), a más de estar «cubierto» por la bóveda celeste.

Ahora bien, ello no significa que el Jardín fuera para Adán un lugar de holganza. En absoluto. El trabajo existía ya en el Paraíso, sólo que era realizado de un modo limpio, sin sudor. ${ }^{5}$ Pues Dios no puso a Adán en tan espléndido lugar

4 Cf. Salmo 8,5-6: «¿Qué es el hombre para que de él te acuerdes, o el hijo del hombre para que te cuides de él? / Y le has hecho poco menor que Dios (Elohim); le has coronado de gloria y honor». Los responsables de la vers. española, Nácar y Colunga, apuntan en nota a 8,5 que el texto es mesiánico, ya que «el hijo del hombre» — según los eds., "el hombre por excelencia»— mienta aquí proféticamente a Jesucristo (B.A.C. Madrid 1958, p. 622, n. 1).

5 Sobre este afán de evitar lo viscoso y fluido (patente para empezar en la humedad que sube de la tierra), cf. mi ensayo Cibersueños xerocatárticos. En: Filosofía para el fin de los tiempos. Akal. Madrid 2000, págs. 119-130. 
simplemente para que gozara de él. ¿Para qué lo hizo, entonces? La respuesta es clara y contundente: "para que lo cultivase y guardase». (Gen. 2, 15). La versión de los LXX es aún más franca: ergázesthai kaì phylássei. El primer verbo está obviamente conectado con érgon: «obra, producto del trabajo». Así que literalmente significa: «trabajar»; en este caso, trabajar la tierra. ${ }^{6}$ Pero, ¿acaso no había creado ya Dios el mundo y decidido además que estaba bien hecho? ¿Qué sentido podría tener entonces trabajar en un Jardín, salvo el de procurar por todos los medios que la tierra, adamah (al fin, el suelo primigenio), no volviera a reivindicar sus derechos, o mejor: su indómita falta de todo derecho, su carácter chtonio, como la serpiente inmiscuida en el territorio acotado? Adán, pues, siendo al cabo también él de «tierra», habría debido guardar... de sí mismo, de sus propias entrañas (y de otros seres de parejo origen rastrero), una plantación, y más: una producción divina establecida contra natura. Es verdad que, viviendo en un régimen divinamente preternatural (pero todavía no artificial, puesto que ser Creador no tiene ningún arte), nuestros Padres, como «pago» a sus servicios de guardeses, tenían fácilmente cubiertas tanto sus necesidades materiales (porque en un régimen hortofrutícola la procura de alimento es mucho más sencilla) como espirituales (a través de la donación de nombre a los animales allí implantados - ¿o trasplantados, mediante selección?-, teniendo por ende dominio simbólico sobre ellos). Tampoco tenían necesidad de guarecerse de las inclemencias meteorológicas, siendo el tiempo intramuros propiedad absoluta del Amo, que por lo demás parecía habitar más en el Jardín —-su residencia de vacaciones, por así decir- que en los cielos. Ni siquiera tras el primer pecado se menciona la necesidad de habitáculo, sino la de trabajo esforzado y sudoroso, parto y muerte: los frutos amargos de la expulsión, debida ésta, por cierto, a una desobediencia perfectamente natural.

Es bien significativo, en efecto, que la única prohibición de Dios a Adán sea la de comer el fruto de un árbol del Jardín, y de que tal árbol sea la sede vegetal de la ciencia del bien y del mal. Pues ciertamente podía haber tenido esa prohibición un carácter, digamos, más «espiritual» (p.e. no dar nombre a un determinado animal, dejándolo en un admirativo y temeroso anonimato; no admirar y aun adorar a las constelaciones del cielo, que al fin muestran cómo medir el otro tiempo: el cronológico, representando el único modelo de lo rectilíneo y por tanto puro, esquemático: sin bulto ni masa grosera, opaca). De modo que la elección por parte del dios plural: Elohim, de un árbol como paradigma de lo prohibido muestra pues por tercera vez la desconfianza divina (celeste) hacia la tierra. Recordemos que la primera señal de degradación de lo telúrico, según el Génesis, se muestra en la tácita equiparación de las aguas inferiores y del abismo, así como en la necesidad de que el «espíritu» (ruah, aliento) de Dios fecunde esas aguas; y la segunda, en la «penetración» de ese aliento en la bien amasada tierra del cuerpo de Adán. Pero, ¿por qué había de depositar el dios el conocimiento del bien y del mal precisamente en un árbol?

6 Así lo emplea también Jenofonte: ergázesthai gên, «cultiver la terre». AleXandre, C., Dictionnaire grec-français. Hachette. París 1878, p. 584, sub voce: ergázomai. 
¿Por qué no guardarlo en su corazón y su mente, o exteriorizarlo en forma de doncella aguerrida, como en el caso de Zeus y Atena? ¿No será — sea permitido musitarlo, no sin temor y temblor-, no será acaso que inquieta la idea de que sea precisamente un árbol —ese ser vivo que se alza al cielo y hunde sus raíces en las tenebrosas y fecundas profundidades de la tierra- el que atesore esa ciencia? Y para el dios del Cielo, ¿no será menos inquietante el que sea otro árbol el que custodie el secreto de la Vida? ¿No dejará todo ello entrever una creencia más antigua, a saber: que el dios depende de que el fruto del árbol no sea ingerido para poder seguir siendo precisamente eso: el dios? ¿No es ésta la sabiduría latente en el primordial roble (o tejo) germánico: Yggdrassil? ¿No estará también en el hecho de que el dios Wotan esté dispuesto a sacrificar un ojo - símbolo de clarividencia y saber - a Erda, la tierra, con tal de que ésta le revele el porvenir? ¿Y no reaparece - travestido- acaso este temor ancestral a la tierra, y al árbol como eje del mundo, en la Leyenda de la Vera Croce, asombrosamente pintada por Piero della Francesca en una iglesia aretina?

Por lo que hace al primer hombre - y por contagio, a todos nosotros-, es el hecho irreversible de la expulsión lo que pone a las claras de relieve nuestra condición existencial (de ex - sistere), a saber: ser un perenne desplazado, sin ocupar un locus naturalis propio: al inicio modelado de la tierra, es llevado luego por Dios al Paraíso para guardarlo, siendo finalmente expulsado de éste, condenado así a volver exul, inops, a su no menos impotente madre. Impotente, porque nada «bueno» brota de ella, siendo como es un caos de maleza, un salvaje desierto sin orden ni concierto. Pero impotente también porque, aunque cabe suponer que Adán y Eva ${ }^{7}$ no dejarían de llevar consigo semillas y renuevos para plantarlos en adamah, esa tierra, aun cultivada, no podía ser desde luego, dado su bajo origen, tan propicia como la del paradigmático Jardín. Es más, así como a la primacía ontológica del hombre preternatural le correspondía la fácil exuberancia del Paraíso, así también su caída implicará la esterilidad y dureza de adamah, la tierra de proveniencia y, ahora, de destino. Al respecto, la maldición que Yavé lanza indirectamente sobre ella no admite lugar a dudas: «Por ti —le dice a Adán- será maldita la tierra [...] Te dará espinas y abrojos. Y comerás de las hierbas del campo». (Gen. 3, 17 y 18). Y a esto le sigue al punto la famosa condena: «Con el sudor de tu rostro comerás el pan». $(3,19)$. ¿Comienza pues de tan extremoso modo el trabajo del hombre sobre la tierra?

Parece que sí, ya que los primeros descendientes de Adán tomarán luego posesión de los dos «reinos» tradicionales de la vida: el vegetal y el animal, mediante la división (propia de la revolución neolítica, diríamos hoy) del trabajo en agricultura (Caín) y en pastoreo (Abel). Y aquí es donde aparece nuestro tenebroso protagonista: el ancestro, nos guste o no, de toda vida ciudadana. Por cierto, con Caín, las referencias a la tierra y la ambigüedad del dios para con este primogénito de Adán llegarán a ser verdaderamente estridentes, como veremos. Que a Caín, por ser precisamente el primogénito, le estuviera destinada

7 Acompañados también — se supone- por los animales, que los siguen obedientes al exilio, pues los primeros Padres conocen su nombre y, llamándolos, pueden congregarlos. 
la continuación natural de la vida humana sobre la tierra (y por ende, el privilegio de empezar ex novo la historia), es algo recogido en el nombre mismo que Eva le impusiera al nacer: la voz qayin (Caín) se halla en efecto estrechamente emparentada con el término hebreo qaniti («he obtenido»). Reza el texto sagrado, siguiendo en esto la tradición propia de los grandes relatos mitológicos - a saber, extraer el nombre propio a partir de la función más relevante de la cosa o persona en cuestión-, que Eva, al parir su primer hijo, le confirió implícitamente el nombre adecuado, al decir orgullosa: «He obtenido de Yavé un varón ${ }^{8}$. Del segundo hijo, Abel, en cambio, no constan en cambio las palabras con que su madre lo hubiera saludado al darlo a luz.

Sin embargo, el Hacedor de Caín no debió de quedar muy satisfecho con el hijo que él mismo había engendrado (si queremos, por causa interpuesta), y que él había también llevado de las entrañas maternas a la luz. El texto sagrado nos dice: «Abel llegó a ser pastor de rebaños, y Caín labrador de la tierra». (Gen. 4,2). Cosa, esta última, bien lógica, a saber: que fuera el primogénito quien hubiera de dedicarse a cumplir al pie de la letra la condena hecha a su padre: trabajar una tierra maldita, llena de espinas y abrojos, a fin de obtener de ella el pan (Gen. 3, 18; ver supra). Así pues, precisamente la dureza del trabajo del labrador, comparada con la facilidad del pastoreo, parece que debiera haber llevado a Yavé a congratularse de la ofrenda de Caín y a encontrar en cambio sin mucho mérito la de Abel.

Por cierto, el texto (como en otros relatos mitológicos paralelos) da por sobreentendida la necesidad de ofrecer en general sacrificios al dios, sin mayor explicación. Ésta, sin embargo, no parece difícil: sacrificar al dios aquello que sostiene a los mortales en vida implica el reconocimiento de que esa vida no es propia, sino concedida, y por tanto puede y debe estar a disposición del concesionario. Sólo que, si la vida humana es concedida, ¿cuál ha de ser la índole de aquello — la ofrenda — que la mantiene por un tiempo? Ya he adelantado la aparentemente obvia respuesta: el sacrificio debería ser tanto más alto cuanto mayor esfuerzo hubiera costado lo sacrificado. Pero, para la óptica bíblica (y no sólo bíblica: recuérdese la Teogonía de Hesíodo), se trata de una apariencia falaz. El sacrificio de un animal (por no decir de un ser humano, como en el caso de Ifigenia, según la saga de la guerra de Troya), el derramamiento de

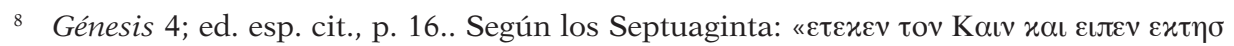

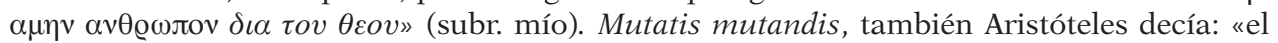
hombre engendra al hombre, y el sol» (en nuestro caso: son Adán y Yavé los que engendran a Caín, pero siendo el primero más bien algo así como la causa instrumental). Más pudibundas y poco comprometidas son la vers. inglesa del Rey Jaime: "II have gotten a man with the help of the LORD" » (subr. mío).- Por lo demás, y en muestra estupenda de lo amplia que puede ser la hermeneusis de los textos sagrados, San Ambrosio retuerce de tal manera el nombre bíblico que lo hace irreconocible. Dice en efecto en De Cain et Abel: «Cain dictus est acquisitio, quod omni sibi acquireret (¡así que Caín era un avaro egoísta, que todo lo quería para sí!, F.D.); Abel qui omnia referret ad Deum, pia devotus mentis attentione, nihil sibi arrogans (eso sí que es ser literalmente desprendido, F.D.).» En: Migne, J.P., Patrologiae cursus completus... Series latina. Garnier Fratres. París 1841-1969; 14, col. 317. 
sangre, supone la pérdida de un ser individual y semoviente, de un ser que ya ha renegado previamente de su pertenencia a la tierra al poder moverse con cierta libertad sobre ella («sepulcros móviles», llamaba Aristóteles al ganado, por su capacidad de acumular el pasto en su interior, para volver a servirse de él a conveniencia). Y más: la renuncia a servirse de la carne por parte del sacrificador, del carnífice, supone a su vez un reniego simbólico de la propia vida, ofrecida así a otra más alta, divina. No es necesario señalar aquí cómo, además, el sacrificio del inocente cordero ha sido utilizado después en la iconografía y en la liturgia cristianas (recuérdese el: «Cordero de Dios, que quitas los pecados del mundo...»).

Por todo ello, resulta mezquina la sospecha (aparte de que el texto nada diga de ello) de que el sacrificio de Caín fuera peor que el de su hermano y de que ello hubiera sido la causa del enojo de Dios, como supone Francisco de Quevedo en un soneto no muy digno de su gloria:

Caín, por más bien visto, tu fiereza

quitó la vida a Abel, porque ofrecía

a Dios el mejor fruto que tenía,

como tú lo peor de tu riqueza. ${ }^{9}$

Por cierto, la propia mención del «mejor fruto» (bien desafortunada, aquí, tratándose de la ofrenda de un pastor $)^{10}$, frente a la alusión a la «riqueza» cainita (como si se tratara de algo conseguido sin esfuerzo), deja entrever de algún modo la inversión del orden «laboral» (y laborioso, más que «natural») a que proceden el poeta español y el autor del Génesis. Otra inversión hay, además, que no debió pasar inadvertida a Caín: siendo éste el primogénito, Abel ofreció sin embargo al Eterno: «los primogénitos de su rebaño, junto con su grasa ${ }^{11}$. De este modo, no parecería sino que Abel estuviera adquiriendo

9 Urania. Sonetos sacros. XIX. En: Obras. Poesías. Ed. JANER, F. Atlas (B.A.E.). Madrid 1953, núm. 69.

10 Por el contrario, y como era de esperar, el texto dice: «sucedió que Caín hizo una ofrenda de frutos de la tierra a Yavé». (Gen. 4, 3).

11 La alusión a la grasa (fuente inmediata de alimentación) parece una reminiscencia de otros viejos relatos. Así, en la Teogonía hesiódica, la krísis, la separación entre dioses y hombres a base del reparto de poder, señalando ditiones (para los dioses el cielo y los infiernos, para los mortales la superficie de la tierra), se saldó en Mekoné con un primer sacrificio a los Inmortales... y un primer engaño a éstos, urdido por Prometeo, «de mente laberíntica y pronta» (Theog., v. 510s.): después de extraer de un buey la carne, rellenó la piel habilidosamente con los huesos, recubriéndolos de brillante grasa, y dio la ofrenda a Zeus, asegurándose de este modo el que los hombres, a pesar de las ofrendas, no dejarían de tener alimento, sino que antes bien se quedarían con la mejor parte. Naturalmente, el piadoso Hesíodo no puede admitir que el Padre de los dioses no se diera cuenta del engaño, pero la explicación que da es - para nosotros - aún peor, pues revela una gran dosis de hipocresía por parte de Zeus (también, como veremos, se dará algo parecido en el caso de Yavé); aquél hizo en efecto como si creyera el engaño, a fin de tener ocasión de irritarse y de proseguir su plan inicial, a saber: llevar a la ruina a los mortales y destruir el género humano para sustituirlo por otra especie 
simbólicamente, a través del sacrificio, el mayorazgo que por nacimiento le había sido negado (no será éste el único caso en la Biblia: recuérdese la bendición de Abrahán a Jacob, en detrimento de los derechos de Esaú). En fin, lo único que sabemos a ciencia cierta es que: «Yavé miró a Abel y su ofrenda, mas no a Caín y su ofrenda. De modo que Caín se irritó sobremanera, abatiendo su rostro». (Gen. 4, 4-5). Tan natural parece entonces, al respecto, la reacción de Caín como ilógica y sorprendente la de Yavé, si alejamos de nosotros - como Dios manda - la idea sacrílega de que Él, en su glotonería, codiciara más la grasa y el unto animal que el régimen vegetariano.

Lord Byron, en su drama Cain, ofrece tácitamente una explicación que resulta mucho más plausible. En primer lugar, se insiste allí en que la ofrenda del labriego es menos sanguinaria: los frutos de la tierra, madurados por el sol, parecen más reflejo de la propia fuerza creadora divina que de la fuerza destructora del hombre (pues que éste habría de arrebatar una vida inocente, cual «sanguinario incienso hacia tus cielos», para ofrecer esa muerte a Dios) $)^{12}$. Y sin embargo, el Eterno no toma en consideración la ofrenda cainita, antes bien: «un remolino echa por tierra el altar de Caín y esparce los frutos por sobre la tierra» (a whirlwind throws down the altar of CAIN, and scatters the fruits abroad upon the earth).

¿Por qué ${ }^{13}$ La respuesta del primogénito desairado es clara y rotunda: porque la víctima animal desaparece para siempre, envuelta en llamas que lamen la sangre quemada y engordan con ella. Por el contrario, aunque se

más «dócil» (cf. Theog., v. 345ss.). La razón era, seguramente, que Prometeo no se habría limitado a robar el fuego divino para dárselo a los mortales, sino también encendido en el interior de éstos un fuego más peligroso y duradero, al «inflamar» la inteligencia técnica de los hombres. Así se gloría en efecto Prometeo: «Les di inteligencia, / haciéndoles dueños de su propio pensamiento». (Theog., v. 633s.).

12 Cain, Act III. Scene 1: «... whose limbs now reek / In sanguinary incense to thy skies; / Or, if the sweet and blooming fruits of earth, / And milder seasons, which the unstained turf / I spread them on now offers in the face / Of the broad sun which ripened them, may seem / Good to thee - inasmuch as they have not / Suffered in limb or life - and rather form / A sample of thy works, than supplication / To look on ours! If a shrine without victim, / And altar without gore, may win thy favor, / Look on it!» (Subr. mío. Hay trad. bil. de López CASTELlón, E. en Abada, Madrid 2011).

13 Para intentar explicar lo inexplicable de la elección, San Juan dice en su primera epístola que Caín mató a Abel porque sus obras eran malas, mientras que las de su hermano eran justas (I Juan 3, 12), lo cual no deja de ser una vacua tautología, mientras que San Pablo se acoge a la fe absoluta en Dios, frente a la debilidad de la razón humana —un tema byroniano, donde los haya-: "por la fe Abel ofreció a Dios un sacrificio más excelente que Caín» (Hebreos 11, 4). Siguiendo al Apóstol de las Gentes, San Agustín interpreta el desdén divino hacia la ofrenda cainita de un modo más sutil. Caín le habría dado una parte de sus bienes a Dios, pero no su corazón (De Civitate Dei, XV, vii). También Byron sigue esta idea: la renuencia de Caín se debe a su necesidad de alzar la propia libertad frente a la «tiranía» del dios, estando aquel aconsejado (no diré yo que mal o bien aconsejado) por Lucifer para que le acompañara en su Non serviam! Libertad apoyada en la razón (y tendente por ello al escepticismo y el nihilismo) contra obediencia basada en la fe (y tendente por ello a la opresión, garante en cambio de seguridad): un tema eterno, que Sartre retomará a su modo en Les mouches. 
consumieran los frutos de la tierra, siempre quedarían las semillas, repitiéndose así el ciclo natural, inmortal en cuanto a la especie. De modo que no importa que los frutos hayan sido arrojados sobre la tierra. Tanto mejor para ésta: «De la tierra vinieron, deja que vuelvan a la tierra. Su semilla hará nacer fruta fresca cuando venga el verano". (From earth they came, to earth let them return; Their seed will bear fresh fruit there ere the summer). El sacrificio de vegetales parece hurtarse así a la supuesta omnipotencia divina; pues la tierra acoge ciertamente a lo muerto, pero para hacer que retornen los frutos a la superficie, una y otra vez: a su debido tiempo. Un tiempo cíclico, horizontal y omnicomprensivo; no lineal, vertical y jerárquico. Un tiempo plural, como plurales son los aiónes, los tiempos propios de cada especie, frente al tiempo marcado de antemano por el dios, el cual otorga según sus designios un tiempo para amar, un tiempo para morir.

Por lo demás, apenas se entiende — salvo que se trate de una sorna tan brutal que sólo puede ser propia de un Amo absoluto- que tras el menosprecio de la ofrenda inocente presentada por Caín (iy en presencia de su hermano menor!), Yavé le pregunte, encima: “¿Por qué estás irritado y está abatido tu rostro?» $(G e n .4,6)$. El versículo siguiente parece contaminado en su última parte. La pregunta inicial del mismo es claramente retórica ( «Si haces el bien, ¿no serás acaso aceptado?»), ya que el único criterio del que Caín dispone para saber si su obra (en este caso, la ofrenda) es buena o no depende de cómo sea recibida ésta por Dios, cuando ya es demasiado tarde para rectificar (al igual que entre los griegos, según Esquilo, si sufrimos, ello es signo de que algo debemos de haber hecho mal): padeciendo aprendemos. A menos que, según estos indicios, lo que se quiera decir - como en el libro de Job- sea algo contundentemente formulado en Proverbios 1, 7, a saber, que: «El temor al Señor es el principio de la sabiduría», de suerte que le será preciso al hombre acatar sin más la reacción divina, por más arbitraria que parezca, y ello a fortiori (¿qué mérito tendría aceptar algo razonable?), con el fin de doblegar cada vez más ante la voluntad de Dios todo conocer y obrar humanos, y ello siempre a posteriori, siempre a las resultas, por así decir.

Por lo demás, como se apuntó, la continuación del versículo es de interpretación controvertida. Los editores de la versión española se inclinan por pensar que Yavé quiere reconciliar al ofendido Caín con su hermano, ya que éste, a pesar de ser el preferido de Dios, no deja por ello de amar al primogénito y de respetarlo como tal, en cuanto princeps de la primera dinastía de la historia humana (lo cual implica, según la promesa de Génesis 1, 28, nada menos que el dominio: "sobre todo cuanto vive y se mueve sobre la tierra»). Así, vierten: «Cesa, que él (e.d. Abel) siente apego a ti, y tú debes dominarle a él». Por el contrario, la versión italiana, con más acuerdo, entiende que no se trata en absoluto de apego al díscolo Caín por parte del buen hermano, sino de acecho por parte del pecado, el cual — con ayuda de Dios- debería ser empero dominado por aquél, con tal de querer hacerlo ( Ma se fai male, il peccato sta spiandoti alla porta e i suoi desideri sono volti a te; ma tu lo devi dominare»). Más radical y plástica aún, aunque en la misma dirección, es la lectura ofrecida en la New 
American Bible: «pero si no (si no obras bien, se entiende; F.D.), el pecado será un demonio agazapado en la puerta, ansiando echarse sobre ti, y sin embargo tú puedes hacerte dueño de él» (but if not, sin is a demon lurking at the door: his urge is toward you, yet you can be his master). ${ }^{14}$ Pero es evidente que Caín no logró dominar a su demonio íntimo (el demonio de los celos y la envidia). Antes bien, éste hizo presa en él, ya que, como reza el texto, lamentablemente demasiado conciso: "Caín hablò con su hermano Abel; cuando estuvieron en el campo, Caín se levantó contra su hermano Abel y lo mató». (Gen. 4, 8).

De entre las múltiples lamentaciones o explicaciones de este primer homicidio quisiera resaltar tan sólo una: la contenida en un inolvidable poema de Antonio Machado, en el que se alzan en aguda contraposición por un lado el gris sombrío del presente, como si estuviéramos al final de una historia (sagrada) ya demasiado cansada para seguir existiendo, y por otro el comienzo terrible de otra versión (profana) de la misma; el maestro apacienta tediosamente a unos niños cansados de vivir antes de empezar a hacerlo, escrutados ellos y él por un dibujo que pinta a lo vivo el pasaje sagrado (el término latino sacrum califica aquello que pertenece al dios, pudiendo por ende ser sacrificado en su honor), como edificación piadosa y a la vez advertencia (no sólo didáctica), no sin la nota grotesca de que el único color que resalta en general de ese ambiente grisáceo, y en particular del aleccionador cartel, sea el rojo de la sangre vertida:

Una tarde parda y fría

de invierno. Los colegiales

estudian. Monotonía

de lluvia tras los cristales.

Es la clase. En un cartel

se representa a Caín

fugitivo, y muerto Abel,

junto a una mancha carmín. ${ }^{15}$

El estigma del primer asesinato se cierne así sobre las miradas infantiles, como una ominosa premonición del pecado español por excelencia, al decir de Machado y de Unamuno: la envidia. Repárese, sin embargo, en que el texto bíblico no dice explícitamente que Caín huyera tras matar a su hermano.

Es verdad que, al igual que siglos más tarde los burgueses responsables de la muerte de Dios no estarán ni con mucho a la altura del magnicidio, negándose

14 Sigo la ed. it. de La Nuova Diodati (La Buona Novella, 1991), la cual, por su acribia, me ha servido también para enmendar tácitamente en algunos pasajes la versión de NácarColunga. Con respecto a la ed. americana, sigo el texto de la Confraternity of Christian Doctrine, Inc., Washington, DC. 1991. En nota 2 ad loc., se apunta a que el término hebreo rebes vale por «demon lurking», o literalmente: «a croucher» (un ser agazapado, como un tigre antes de saltar sobre su presa).

15 Recuerdo infantil. En: Proverbios y cantares. Poesías completas. Espasa-Calpe («Austral»). Madrid 1962. 
en consecuencia a aceptar lo que sin embargo han hecho ${ }^{16}$, así tampoco la actitud de Caín puede tildarse desde luego de gallarda. Por lo demás, tampoco la retórica pregunta de Yavé («Abel, ¿dónde está tu hermano?»Gen. 4, 9), propia de un inquisidor policial, deja mucho espacio al lucimiento. Sea como fuere, la respuesta de Caín, tan cínica como altiva ( No lo sé; ¿soy yo acaso el guardián de mi hermano?»), es desde luego decepcionante. Aunque con ella devuelva no menos retóricamente la pregunta al Amo de la finca (supuestamente situada a las afueras del Jardín), y con razón, por ser Él quien de verdad custodia y vigila (su función parece ser ante todo surveiller et punir, como dirá Foucault mucho después), yo estaría por decir que, al menos aquí, la réplica de Caín no es desde luego tan profunda (aquí no se puede hablar de "estar a la altura») como debiera haber hecho, saliendo en defensa del ser-de-la-tierra, pues que pertenece a ella y en ella trabaja. Por el contrario, en un espectacular cruce de funciones, es ahora Yavé quien toma a su cargo esa defensa: "¿Qué es lo que has hecho? La voz de la sangre de tu hermano me grita desde la tierra. Desde ahora maldito serás por la tierra que ha abierto su boca para recibir la sangre de tu hermano, derramada por tu mano». (Gen. 4, 10-11). La imagen es desde luego magnífica. La misma boca de la tierra que acusa ante Dios al fratricida es la que - maternal al fin- absorbe la sangre derramada: una sangre que no ha sido quemada en sacrificio ni, por tanto, convertida en humo oloroso, grato al Señor del Cielo, sino que, al contrario, pesada y densa como la misma tierra, vuelve a ella, contaminando su función generadora de lo viviente.

Pero para intentar comprender lo que el texto nos vela, esto es: la reacción de Caín ante su crimen, y la tragedia íntima de su fidelidad adámica a la tierra en cumplimiento de la condena divina, el drama de Lord Byron resulta insustituible. En efecto, Caín ha sido presentado como hombre de arrebatos coléricos, como muestra de su profunda inseguridad respecto a su propio estatuto esencial y a su destino en la tierra (en hondo contraste con Lucifer, que esgrime ante el vacilante primogénito una panoplia espléndida de armas para luchar en su satanismo - et pour cause - contra el Enemigo vencedor y unir a hombres y a espíritus caídos — no parece haber otros, ya que para él es Dios, por decirlo ahora con Schiller y Hegel: «el solitario sin vida»). ${ }^{17}$ Ello es indudable. Pero tampoco cabe duda de que él se rebela precisamente contra su Señor en nombre de una inocencia del devenir todavía un tanto lánguidamente romántica, todavía no nietzscheana. Una inocencia «natural» pacífica, y más: pacifista, contra todo derramamiento de sangre, contra toda muerte de víctimas inocentes realizada

16 Ver el famoso § 125 de La gaya ciencia, de Friedrich Nietzsche.

17 Cain, op. cit. Act I, Scene I (Lucifer habla a Caín, refiriéndose a Dios): «But let him / Sit on his vast and solitary throne, / Creating worlds, to make eternity / Less burthensome to his immense existence / And unparticipated solitude; / Let him crowd orb on orb: he is alone / Indefinite, indissoluble tyrant». A pesar de la innegable grandeza de estos versos, cabe recordar, obviamente, que Dios no está solo: al final del drama de Byron, es un Ángel el que pone la marca del Señor sobre la frente de Caín.- La alusión a Schiller y a Hegel remite respectivamente al poema Resignación y al final de la Fenomenología del espíritu. 
de manera cruenta para complacer a un dios que reivindica para sí la capacidad de engendrar por un lado la vida (repárese en que si Eva recibió de Dios a Caín a través de Adán, su padre biológico, en la Persona del Espíritu Santo será infinitamente mayor la fuerza genesíaca divina, ya que, en el caso del nacimiento de Jesús, José ni siquiera conoció a María). Pero también se arroga en exclusiva, por otro, el poder de dar la muerte. Aquí, ciertamente, el Eterno parece estar desde luego más allá del bien y del mal, pues que tanto lo uno como lo otro se define tan sólo en función de la obediencia o desobediencia de Abel o de Caín ante mandatos que, para el estrecho cacumen del hombre normal, parecen ser desde luego arbitrarios, y que además solamente después, cuando ya es demasiado tarde, pueden ser reconocidos como criterio de actuación.

Y sin embargo, de seguir el romántico viraje que imprime Byron a tan original historia, Caín habría dado la muerte a su hermano precisamente por querer llevar al extremo su defensa de la vida de seres inocentes, ofrendados sin culpa alguna a un Señor despótico. ${ }^{18} \mathrm{He}$ aquí lo trágico de su situación. Por cierto, como señala de modo soberbio el poeta, Caín ni siquiera sabe al pronto que ha dado la muerte a su hermano, ya que todavía no conoce lo que sea la muerte. Sabe, sí, que ellos - los hombres- están condenados por la Caída a ser mortales, pero no entiende que el cuerpo de su hermano esté inerte ante él. Por eso no huye: antes bien, se queda estupefacto a la vista del cadáver. Tampoco, de seguir la interpretación del poeta inglés, parece justa la imprecación de Yavé sobre la sangre derramada del hermano. Para Caín - animal terrestre, al fin- esa sangre es también la suya. Con su acción, tan impulsiva como poco meditada, él se ha puesto fuera de la corriente continua de la Vida. ${ }^{19}$ Oscilando entre la estupefacción y la desesperación, Caín habrá de aceptar la condición propia del homo necans.

Y es de nuevo la pobre, castigada tierra la que recibe otra vez la maldición que ya recayera sobre Adán y su descendencia: «Cuando cultives el suelo —advierte el Señor a Caín-, éste te negará sus productos, y tú serás vagabundo y fugitivo sobre la tierra». Pero aquí sí, aquí Caín, en su mezquindad de homicida incapaz de cargar con su propia culpa, se revela como un excelente estratega. Se queja primero ante Dios del castigo que le ha sido impuesto, arguyendo implícitamente que éste ha sido injusto (pues, cabe suponer, jél no quería matar a su hermano!; por cierto, ni siquiera sabía qué era eso de matar o morir, ni cómo hacerlo): «Entonces Caín dijo al Eterno: Mi castigo es demasiado grande para

18 Sacrificados, como Abel le recuerda, para satisfacer el placer del Señor, regocijado en el sacrificio. Ante esa alegría en el mal ajeno, Caín, airado y con despecho, se revuelve: «His pleasure! what was his high pleasure in / The fumes of scorching flesh and smoking blood, / To the pain of the bleating mothers, which / Still yearn for their dead offspring? or the pangs / Of the sad ignorant victims underneath / Thy pious knife? Give way! this bloody record / Shall not stand in the sun, to shame creation!» (Act III, Scene I).

19 Ibid.: «Tis blood - my blood - / My brother's and my own! and shed by me! / Then what have I further to do with life, / Since I have taken life from my own flesh? / But he can not be dead! - Is silence death? / No; he will wake; then let me watch by him. / Life cannot be so slight, as to be quenched / Thus quickly! 
que yo lo pueda soportar. Y así, al expulsarme tú hoy de la faz de este suelo y ocultarme tu rostro, seré vagabundo y fugitivo por la tierra, de modo que quien me encuentre me matará». (Gen. 4, 13-14). La argumentación extraña un poco, prima facie: se supone que todavía no existía nadie (salvo sus propios padres) que quisiera matarlo (aunque, a juzgar por la reacción de Eva en el drama de Byron, a la vista del cadáver de Abel, quizá tenía después de todo Caín sus motivos para temer la ira materna más que la cólera del Señor). Además, el fratricida bien podría pensar que quisieran vengar a Abel tanto su hijo Enoch (que en el drama de Byron ya existe) como, en el futuro, los hijos que todavía pudieran tener sus padres (habida cuenta de que, según el Génesis, Adán habría de vivir 930 años), Sea como fuere, la actitud de Yavé frente al primer homicida de la historia no deja de sorprender. No sólo, como habría cabido esperar siguiendo la Ley del Talión, no lo mata (Él, que tanto placer sentía ante las víctimas humeantes en los altares a Él dedicados), sino que se limita a desterrarlo, a hacer que salga de su "presencia», por más que ésta fuera ya sólo transmisible a través de su Voz (lo cual significa que aun fuera del Jardín seguía ejerciendo vigilancia sobre la primera familia por Él creada), sino que, además, lo «marca» con una suerte de tatuaje-salvoconducto impreso en la frente del homicida: «Por esto, quien matara a Caín castigado será siete veces. Y el Eterno puso un signo sobre Caín, a fin de que ninguno, encontrándolo, lo matase». (Gen. 4, 15). Por cierto, si el signo debía de ser ciertamente salvífico ad extra, no parece que sus efectos ad intra fueran tan benéficos, ya que, de seguir a San Jerónimo (quizá extrañado de que Dios tuviera tantos miramientos con el primer asesino), ese signo habría convertido a Caín poco menos que en un epiléptico, lleno de temblores corporales y de agitación anímica. Quevedo, en el primer terceto del soneto ya mencionado, ha sabido mostrar ese estado de modo certero:

Temblando vives, y el temblor advierte,

Que, aunque mereces muerte por tirano,

Que tiene en despreciarte honra la muerte. ${ }^{20}$

A pesar de la innegable fuerza hiperbólica que tienen las palabras de nuestro gran poeta y notorio antisemita, las presumibles razones de Yavé (si es lícito escudriñar pedem aliquantulum la insondable mente divina) parecen más prosaicas, y recuerdan más bien un donoso pasaje de La venganza de Don Mendo, de Pedro Muñoz Seca, en el que el protagonista se irrita contra su frustrada enamorada morisca por haber apuñalado ésta a Magdalena: la ingrata, casquivana y en fin adúltera amada de Don Mendo, el cual, airado, espeta en efecto a

20 Claro que la marca y la prohibición de matar a Caín y su descendencia podían ser interpretadas de modo mucho más siniestro. Así, el Obispo de Lincoln establecería en el año 1235 (con luengas consecuencias posteriores para cuantos siguieron `piadosamente su ejemplo) que los judíos debían ser esclavos de los gobernantes de la tierra, declarando que, por tener encima la marca de Caín, habían de ser condenados a vagar por la tierra para siempre (lo que significa, en un régimen feudal: el no poder ser propietarios de tierra alguna), pero sin matarlos, a fin de que cumplieran la condena de Caín. 
la atribulada Zoraida: «¿Qué has hecho, maldita mora? / ¿En quién me vengo yo ahora?» Y es que hay que recordar, dicho sea con todo respeto, que el escriba humano del Génesis era obviamente posterior a los sucesos que él estaba narrando (y ello, por no hablar de San Agustín, que necesitaba justificar por este crimen preliminar su distinción famosa entre la ciudad de los hombres o del mundo y la civitas Dei). Yavé, o su escriba, precisaba desde luego dejar en libertad a Caín para que éste tuviera descendencia, ya que de ese modo se aseguraba que los «hijos de los hombres» tuvieran mujeres tan hermosas (el texto sagrado no aclara por qué razón lo eran, en comparación con la otra estirpe, la bendita) que los hijos de Dios, es decir, los descendientes de Seth, el nuevo Abel, ${ }^{21}$ se enajenaran de tal modo al verlas que "tomaron de entre ellas por mujeres a las que bien quisieron». (Gen. 6, 2). Lo cual, a su vez, permitirá que Yavé exteriorice su cólera contra deseo tan terrestre: "No permanecerá —se dijo entonces- por siempre mi espíritu en el hombre, porque éste no es más que carne». Atiéndase a la razón: el hombre no es más que carne, o sea tierra, y no merece ser receptáculo del aliento divino. Así que, para acabar con tal lacra, decretó el diluvio universal: el agua, contra la tierra. Por consiguiente, por no haber sido muerto el primer homicida pereció después toda la especie humana, salvo Noé y su descendencia. Y más: si Yavé no hubiera extendido entonces un salvoconducto para Caín y su prole, ¿cómo habría podido establecer San Agustín ex post festum la famosa distinción ya aludida?22 (Dicho sea de paso: parece que incluso en la descendencia de Noé se había inmiscuido algún hijo de los hombres - posiblemente Jafet, ya que los camitas sólo valdrán como esclavos-; pues de lo contrario no se ve de dónde habría salido la civitas mundi, si es que debemos ser fieles a la obstinada atenencia al mito de los orígenes que se respira en todo este relato inaugural de la historia humana, y en su interpretación por los Santos Padres).

Sea como fuere, lo relevante del caso es que, al contrario de la condena dúplice de trabajar la tierra, Caín es el primer hombre que conscientemente desobedeció una orden divina. Si la muerte de Abel fue, según indicios razonables, accidental y desde luego no premeditada ni querida, el primogénito de Adán no estuvo dispuesto desde luego a vagar fugitivo por toda la haz de la tierra, por más que así lo impusieran los piadosos carteles de la España profunda, tácitamente denunciada por Antonio Machado. Muy al contrario, y siguiendo el reiterado ejemplo de Adán, su padre: «Caín conoció a su mujer, y ella concibió y

21 También aquí nos encontramos con un juego de palabras parecido al de Caín/qayin. En una evidente repetición del comienzo de la historia (dado lo fallido del primer inicio), el texto dice que Adán volvió a conocer a su mujer, la cual, al dar a luz a Seth, exclamó: «Me ha concedido Yavé otro descendiente por Abel». (Gen. 4, 25). «Haber concedido» es, en hebreo, shat, de donde Shet o Seth. Igual ocurrirá con el hijo de Seth, Enosh, primero en establecer un culto público a Yavé. En evidente semejanza con el hijo de Caín, Enoch: ambos nombres remiten a un sinónimo de adam, o sea: el hombre.

22 Cf. De civitate dei; XV, i-viii. Por lo demás, recuérdese que también Zeus hizo que creía en el engaño para poder arruinar así a los hombres (eso sí: de un modo mucho más lento y placentero, a saber: forjando a la primera mujer, Pandora). 
parió a Enoch. Caín construyó después una ciudad, a la cual llamó Enoch, por el nombre de su hijo». (Gen. 4, 17).

No puede decirse que fuera una descendencia insignificante: el tataranieto de Enoch, Lamech, se identificará con Caín hasta tal punto que repetirá en favor propio la promesa que Dios diera a su poco ilustre ancestro, pero siendo él ahora quien amenaza con tomarse la venganza por su mano: «Mujeres de Lamech, oíd mis palabras: Por una herida mataré a un hombre, y a un joven por un cardenal. Si Caín sería vengado siete veces, Lamech lo será setenta veces siete» (Gen. 4, 23-24) ${ }^{23}$. Pues bien, este jactancioso espadón "obtuvo» de Adah — una de esas mujeres obedientes - a Jabel (primero en dedicarse al pastoreo; se supone que después del frustrado comienzo de Abel, cuyo nombre imita) y a Jubal, el primero en componer música. Pero más importante es el hijo habido de la otra mujer, Sela, a saber, Tubalcaín (en el cual, evidentemente,resuena el nombre execrable: qayin), y que hace las veces de un Hefestos hebreo y mortal, por haber sido el primero en fabricar armas y aperos de bronce y de hierro. Con ello, la descendencia de Caín se procuraba desde luego, a través de la técnica prometeica, un lugar importante en la historia, por profana que ésta fuere.

Pero en fin, no hay desde luego nada comparable en consecuencias - que llegan a nuestros días y se extienden como una mancha de aceite sobre toda la haz de la tierra- como la desobediencia de Caín al mandato de Yavé, a saber: que el homicida fuera un vagabundo sobre la tierra. En efecto, Caín podrá por siempre lucir para bien y para mal el título de primer constructor de ciudades. Una ciudad ligada no tanto al asesinato del hermano cuanto, sobre todo, a una argucia técnica para esquivar la maldición de Yavé, para evitar el destino. Como vimos, Dios, en sus designios (en este caso fácilmente escrutables), habría decidido ab initio que el rasgo esencial de Caín: el sedentarismo del labrador, su apego a la tierra, habría de tener un carácter degradante. Sólo que, contra la expresa voluntad divina, el labrador Caín no sólo no se «reconvierte» al nomadismo del pastor (nómada y pastor será también, en cambio, el «tercer» Abel, tras Seth: Abrahán, el fundador del Pueblo Elegido), sino que, «lejos de la presencia del Señor» (Gen. 4, 16), echa raíces en el doble sentido de la palabra: tiene un hijo y funda una ciudad (o mejor: funda la ciudad).

Según el Génesis, pues, el origen de la ciudad no se debe únicamente - siquiera sea de modo mediato- al Crimen primigenio, sino a algo mucho más grave: Caín se niega a obedecer a Yavé y, en su hybris técnica, "dejada de la mano de Dios», se afinca definitivamente, él y su descendencia, en un sitio fortificado, forjando ciudades amuralladas con un doble cerramiento: 1) horizontal y periféricamente, estableciendo así la distinción entre campo y ciudad; 2) verticalmente, techando las viviendas y almacenes del interior de la ciudad,

23 Lamech tuvo dos mujeres, Sela y Adah. El fecundo ingenio de Byron aprovecha en su drama esos nombres para convertir a sus portadoras en las mujeres de Abel y Caín, respectivamente. 
para protegerse de un cielo que ha dejado de ser protector. El hombre cainita (el hombre de ciudad, "civilizado») establece su morada a la contra: contra la tierra - que según la maldición divina habría de negarle sus frutos- y contra el cielo, hostil y amenazador. Literalmente, la habitación humana se yergue desde entonces, desafiante, en medio de lo inhóspito (o como dicen los italianos para nombrar lo siniestro: lo spaesante, aquello que reniega de todo paese -la aldea rural - y de todo paesaggio — el paisaje envolvente y protector). Literalmente, también, el primer ciudadano surge del delirio por escapar de la mirada de un dios que ya no se deja ver: "En el principio era el delirio, lo cual quiere decir que el hombre se sentía mirado sin ver. Que tal es el comienzo del delirio persecutorio: la presencia inexorable de una instancia superior a nuestra vida que encubre la realidad y que no nos es visible». ${ }^{24}$

El dios no nos es visible. Dejó de serlo cuando Caín emprende un segundo y definitivo exilio del hombre respecto de Dios. Y así: «alejándose de la presencia del Señor, habitó la región de Nod (el país de los que huyen: el término remite a nodedim, «los fugitivos»; F.D.), al este de Edén (o sea, más al este aún que el Jardín, F.D.)». (Gen. 4, 16). Nunca más volverá el hombre a ver a Yavé-Dios sobre la tierra (se entiende, en su morphé theoû, no en forma de siervo, como Jesús). Sólo a algunos privilegiados se les concederá oír su voz tonante, para transmitir órdenes y amenazas a su pueblo. Pero su visión sobre todos y cada uno de los hombres (también pues sobre los pueblos no elegidos: los bárbaros y los gentiles): literalmente, su supervisión, seguirá siendo exhaustiva, continua y completa. Y es que por la visión se elige (se escoge, p.e., atender a tal o cual cosa). En la audición, en cambio, se es elegido, sorprendido.

La vista permite el control, el dominio y el mantener a raya, a distancia, el objeto contemplado («respecto» y «respeto» vienen del mismo término latino: respectus). Tal parece que en la visión uno eligiera su presa, de entre todas las que contiene el ancho mundo. Ver sin hablar, sin ser notado: tal es el ideal del cazador y del voyeur, que son (valga la redundancia) depredadores de presas. Por el contrario, el punto álgido de la audición sería (considerado desde el oyente, claro) el delirio de sentirse observado (puesto que se le está hablando a él en particular, es que alguien lo está viendo y fijando, como una presa), la desazón de sentirse visto sin poder ver a su vez. Algo así debió de sentir Caín cuando oyó resonar por todas partes la voz acusadora de Dios. La audición delirante «sobrecoge», lo toma a uno por «sorpresa». Ya el mero «tener que oír» le recuerda al hombre su carácter finito, mortal. Sólo por bondad, y no por necesidad de reciprocidad, el dios escucha. Y al contrario, si el dios habla es porque el Lógos endiathetós (Verbum interius), al volverse Lógos prophorikós (Verbmu exterius), deviene la fuerza creadora de las cosas todas, y especialmente de los hombres, los únicos que, habiendo nacido de la Palabra, pueden corresponder a ella. Pues, de seguir la lapidaria afirmación de Schelling en su Freiheitsschrift: «Él habla y ellos (los hombres, F.D.)

24 María Zambrano, El hombre y lo divino. F.C.E. México 1955, p. 31. 
existen (Er spricht und sie sind $d a)_{»^{25}}$. Ahora bien, la Palabra remite a la Visión, pues, por lo que respecta al dios —y sólo a él—, su esencia consistiría en la pura visión... de sí mismo, de un solo golpe de vista (uno intuitu) en el cual vería - si se trata del dios tomista, y no del aristotélico— - todas las cosas: como si se tratara de un espejo creador, y no simplemente reproductor.

Delirio debió de ser pues — según María Zambrano- lo sentido por Caín al preguntarle Dios por su hermano. Delirium se deriva del verbo deliro: «salir, desviarse del surco». La máxima pena para un labrador, ciertamente. Mas a ese delirio (resultado de la mirada implacable de un Dios oculto sobre el criminal, que en cambio queda al descubierto) corresponde Caín con otro, si no más eficaz, sí desde luego más astuto y retorcido: se libra de esa mirada que lo angustia y condena estableciendo una ciudad prediseñada sobre la tierra mediante una cuadrícula que "rectifica», aquí abajo, el orden celeste, apuntando a los cuatro puntos cardinales (la urbs quadrata romana); o bien, mediante una continua desviación del surco del arado, dibuja una circunferencia y, por ende, un centro desde el que poder -invirtiendo la anterior relación de dominación delirante- mirar sin ser visto, como en una atalaya fortificada.

El hombre de ciudad usurpa el lugar de Yavé Dios: se convierte en ojo que domina desde lo alto y en mano armada (Tubalcaín) que rechaza al enemigo con «instrumentos cortantes de bronce y de hierro»(Gen. 4, 22), rasgando con ellos también la tierra - antes sagrada- para forzarla a entregar sus frutos. Con la ciudad, el hombre establece una nueva distinción de espacios: esta vez, técnica y profana. Ya no habita el oasis, gracias al cual se halla pasiva y precariamente protegido del desierto, el cual lo cerca horizontalmente, al igual que la supervisión divina lo hace verticalmente. Ahora es un habitante de la ciudad, de modo que domina así activamente los campos y, ad limitem, otras ciudades y otros hombres (extendiendo la vista en un movimiento centrífugo, humano).

La fortificación, la agricultura como «industria» sometida a reglas técnicas, y el arte de la guerra nacen a la vez. Y con ellas, la planificación y ordenación del mundo a imagen y semejanza del técnico ciudadano. Nada más significativo al respecto que la familia semántica de la que, en los pueblos germánicos, ha brotado la idea de «espacio»: Raum (al.), room (ingl.), procedan de "ruma («vasto», espacioso»: al. geräumig). Esta misma raíz se encuentra en la voz latina rus (el «campo», lo «rural»), de donde procede también el verbo aro (gr. aróo), es decir: «arar». Así que al mismo «campo» corresponde también —nunca mejor dicho- el término «arado». Y además, la prolongación metálica, hostilmente rígida, de nuestra mano (la «reja» del arado), es el origen primero, técnico, de toda apertura de espacios. El hombre descarriado, de-lirante, se hace de este modo fuerte en el exilio, hace de la necesidad virtud y se arraiga

25 Schelling, F.W.J., Philosophische Untersuchungen... (Cotta Ausgabe; S.W. VII, 347). La ed. esp.: Investigaciones filosóficas... (Anthropos. Barcelona 1989) recoge también la paginación original. 
en el desarraigo mismo, delimitando los espacios de su actividad a partir de un centro: la futura «capital» (de caput, cabeza) de una comarca.

Sin embargo, ese dominio, esa ditio no se establece sin continuas transacciones. Pues la comarca artificial (una redundancia, ésta: en la naturaleza «virgen» no hay contrade, ni countries, ni contrées) se asienta en un paraje natural, en una región ya de antemano configurada por desiertos, ríos, bosques y montañas, y con la que es preciso aprender a "convivir». Por eso, en un gesto que es a la vez desafío y homenaje a las fuerzas divinas, ubica el hombre en el centro de la ciudad una montaña artificial (el ziqurrat mesopotámico, la pirámide zapoteca o azteca) o sitúa en las alturas que dominan la ciudad templos - como en la Acrópolis griega - en los que los dioses celestes puedan hacer acto de presencia. Templos que guardan a su vez en el centro de la náos la oquedad por la cual —oficiando ésta de hueco axis mundi- se comunica lo celeste con los inferos, con las divinidades del subsuelo, hipoctonias.

$\mathrm{Al}$ respecto, en el otro gran mito antropogónico que está a la base de nuestra cultura: Erga kaì Hemeraí, de Hesíodo, la primera mención de la habitación humana está estrechísimamente enlazada con la premonición del crimen generalizado: la guerra, y con el culto a los ancestros, divinizados como «beatos mortales, subterráneos (hypochthónioi), [demonios] segundos» (vv. 141s.; se entiende: «segundos», respecto a los dioses olímpicos).

Es verdad que el relato hesiódico guarda algunas semejanzas con el del Génesis: los primeros hombres reciben alimento de la tierra, sin penas ni trabajos llenos de sufrimiento y pesar; la segunda raza - mutatis mutandis, los «cainitas» fratricidas y fundadores de ciudades- olvida en cambio lo divino y pretende hurtarse a la mirada de Dios, de modo que en esta era aparece la habitación humana a la vez que la guerra y la muerte violenta. Con todo, en Hesíodo encontramos dos diferencias fundamentales, que ofrecen otro rasgo capital — esta vez, positivo - del habitar la tierra por parte del hombre. Para empezar, que dentro de la ciudad está la casa, el oikós amorosamente protegido por la madre, y en el que se desarrolla la infancia entre juegos. Pero además, y como recuerdo de ese período de segunda inocencia matriarcal (frente a la primera, patriarcal), en la casa se rinde honor a las ya mencionadas divinidades hipoctonias (¿el fantasma de Abel, quizá?), extrañamente consideradas como «mortales», frente a los primeros seres bienaventurados que, a pesar de haber muerto como «rendidos por el sueño», vagan ahora sobre la haz de la tierra (epictonios), protegiendo como ángeles a los viajeros. Todo ello hace suponer que la muerte dulce de la Edad de Oro debe considerarse como algo bien distinto a la muerte violenta de los hombres de plata y a la de los hombres de nuestra última y degenerada raza, cuyos muertos quedan bajo la guarda de las también «muertas» divinidades subterráneas, si es que no acaban por identificarse con ellas.

Uniendo pues los ritos mosaico y hesiódico, podemos decir que la ciudad es agresivamente centrífuga, portadora de muerte violenta ad extra, y está en manos de hombres adultos que «abren» espacios por el trabajo, la quema y tala de árboles y maleza selvática (roza), y la guerra, mientras que la casa, en el interior 
de la ciudad, es pacíficamente centrípeta, protectora de la infancia bajo la mirada de la madre. Y además, en la casa se rinde culto a los muertos. Por esta conmemoración piadosa, empero, ingresa en la «paz del hogar» el viento impetuoso de la antigua violencia viril, sin la cual la casa misma no podría subsistir. La casa aparece así como un intervalo maternofilial, pacífico y precario, de una violencia en todo caso interiorizada, y entronizada en ella por el recuerdo. De nuevo, paz en la guerra: hospitalidad en el seno mismo de lo inhóspito. En el interior de la casa reaparece pues —en pequeña escala y como sublimadoel drama arcaico de las contraposiciones: la Madre (Jardín-Campo labrado) guarda al hijo de plata (esto es: a aquel que recibe su luz y sentido de una raza ya extinguida: la áurea), al infans: el todavía carente de palabra. Además de ello, en el hogar se rinde culto - en una memoria que abarca a la vez pasado y futuro- al antiguo y colérico padre apartado y al hijo que, en el porvenir, violentamente matará y violentamente será muerto, como Lamech, por defender la Ciudad y extender sus límites, hasta convertir una de ellas en caput mundi.

De esa tensión, del peso de la Tierra-Madre sobre nuestras decisiones, y de las ansias de saber por parte de un masculino lógos insaciable (pues que, no en balde, la expulsión del Paraíso es precisamente consecuencia de esa ansia del primer hombre por conocer el bien y el mal), surgirán, siguen surgiendo la miseria y la muerte.

Tal es el mysterium iniquitatis, presente en el Caín byroniano. Sólo una débil esperanza nos anima: la de que, a pesar de todo, arraigue y fructifique el ejemplo sencillo de una mujer: Adah, que en el drama poético se niega a abandonar a Caín, el homicida, a pesar de que éste sabe muy bien que nunca encontrará la paz. Es el amor que redime en la carne la herida del Espíritu. Un amor de piedad y sacrificio. Un amor viejo, obstinado y silencioso. Un amor que sabe a agua y a tierra, capaz de tornar la sangre en savia. Un amor que seguramente los antiguos no conocieron.

Universidad Autónoma de Madrid

felix.duque@uam.es

FÉlix DuQue

[Artículo aprobado para publicación en diciembre de 2015] 